\title{
Improving Performance of Type T Overhead Rigid Conductor Lines
}

\author{
Masatoshi SHIMIZU \\ Senior Researcher,
}

Satoshi HARADA

Assistant Senior Researcher,
Akinori OYA

Assistant Senior Researcher,

Contact Line Structures Laboratory, Power Supply Technology Division

\section{Koichiro TOKUDA}

Formerly with the Contact Line Structures Laboratory, Power Supply Technology Division

\begin{abstract}
Because of their simple structure and low-maintenance characteristics, railways in Japan have often adopted overhead rigid conductor lines for current collection systems applicable to underground track sections or tunnels. With regard to the copper Type T rigid conductor line adopted on some JR commercial lines, undulating wear appeared at intervals of about $60 \mathrm{~mm}$ on contact wire sliding surfaces. Such wear would cause impaired train speedup and thus increase maintenance costs. We investigated the causes of the wears, and proposed measures to improve the quality of overhead rigid conductor lines.
\end{abstract}

Keywords: Overhead rigid conductor line, contact wire, undulating wear

\section{Introduction}

Because of their simple structure and low-maintenance characteristics, copper Type T rigid conductor lines have been provided on underground track sections or in tunnels on some JR commercial lines, such as the JR Tozai Line in Osaka. The system has fewer parts compared with those required for an overhead catenary line system. In addition, as copper is used for the Type T mount and other conductor line components, it is resistant to corrosive environments. Therefore, copper Type T rigid conductor lines offer effective low-cost maintenance benefits.

However, undulating wear on the sliding surface of the contact wires occurred at regular intervals of about $60 \mathrm{~mm}$ soon after the line was commissioned for revenue service. When such a phenomenon appears, the contact wire wear rate and contact loss rate significantly increase, which will very likely impair train speedup and incur additional maintenance costs. The purposes of this study were to investigate what is causing the problem and to propose measures to improve conductor line quality.

From the results obtained with a rigid conductor line temporarily installed on RTRI premises, it was evident that the formation of unevenness with a characteristic wavelength depends on the various types of contact wires and construction methods used. In addition, after removing the unevenness on the sliding surface on a JR commercial line, the difference in current collection performance before and after the remedial repair, and the subsequent change to the sliding surface were verified. As a result, it was apparent that contact wire unevenness adversely affected the contact loss and that undulating wear was never generated on the sliding surface of a sound contact wire.

\section{Outline of facility provisions}

Fig. 1 shows an outline of the JR Tozai Line. The tunnel section in which a copper Type T rigid conductor line was installed, is $10.2 \mathrm{~km}$ long. Fig. 2 shows a tunnel cross section and Fig. 3 the structure of a Type T rigid conductor line. The rigid conductor line is equipped with continuous mounts, each one of which is $7.5 \mathrm{~m}$ in length and jointed with a splicer that is supported at 5-meter intervals. In addition, a GT-Sn $170 \mathrm{~mm}^{2}$ (grooved trolley $\mathrm{Cu}-$ Sn $0.3 \%$ ) contact wire is fitted with ears underneath the mounts; the ears, each one of which is $1200 \mathrm{~mm}$ in length and has button bolts, are fitted at intervals of $400 \mathrm{~mm}$. Fig. 4 shows a pantograph of the type of train set mainly operated on this line. The pantograph has two pantograph heads: each pantograph head has two sintered-copper metal sliders, which are separated by about $60 \mathrm{~mm}$.

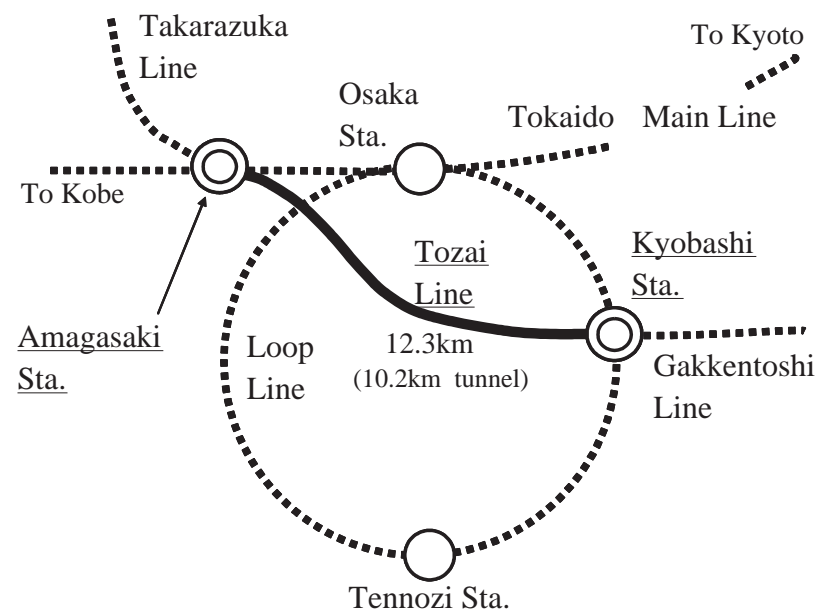

Fig. 1 Outline of JR Tozai Line 


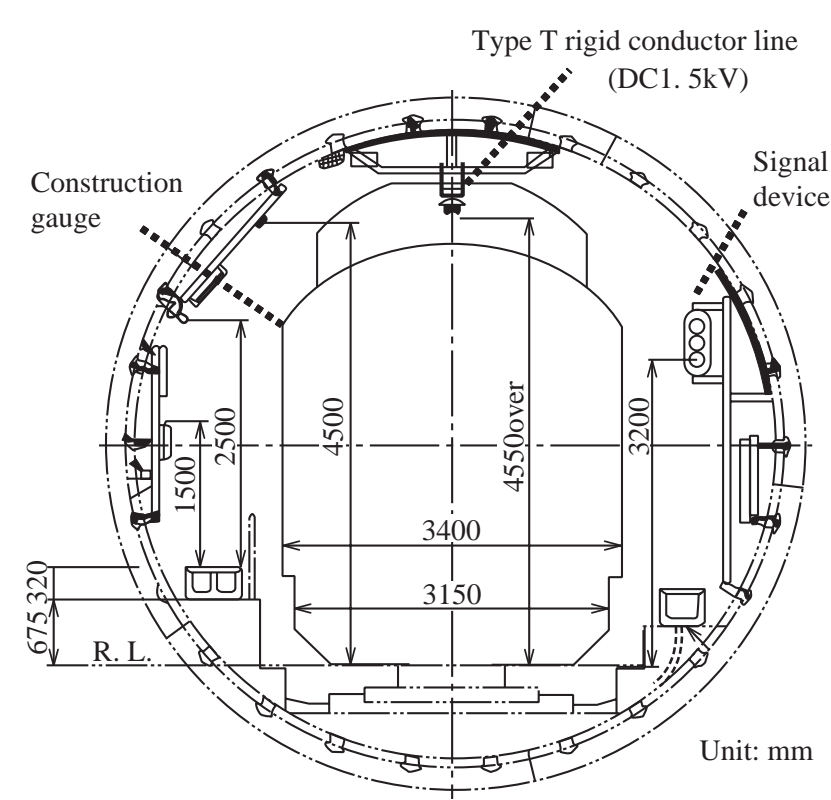

Fig. 2 Tunnel cross section

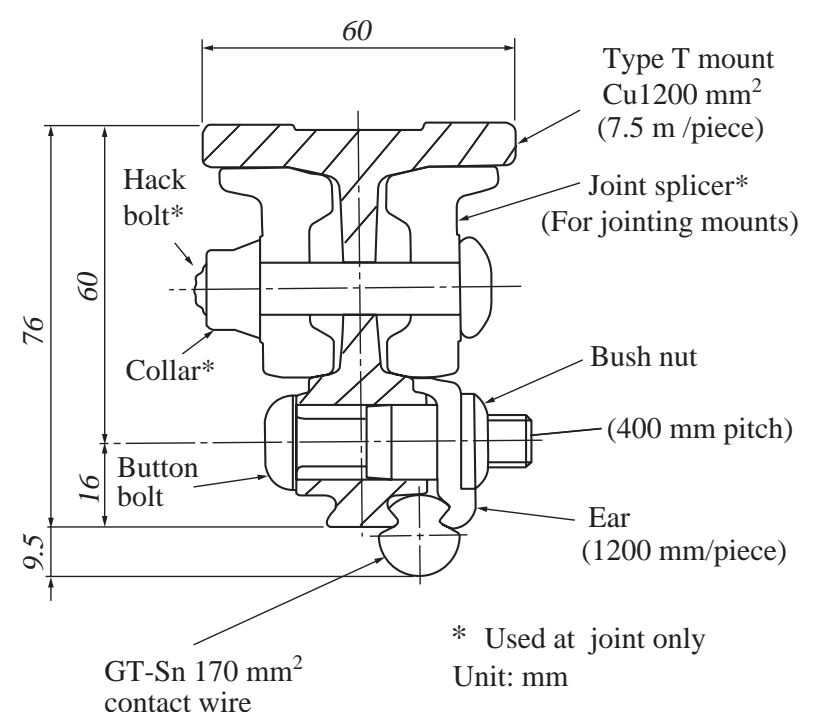

Fig. 3 Type T rigid conductor line

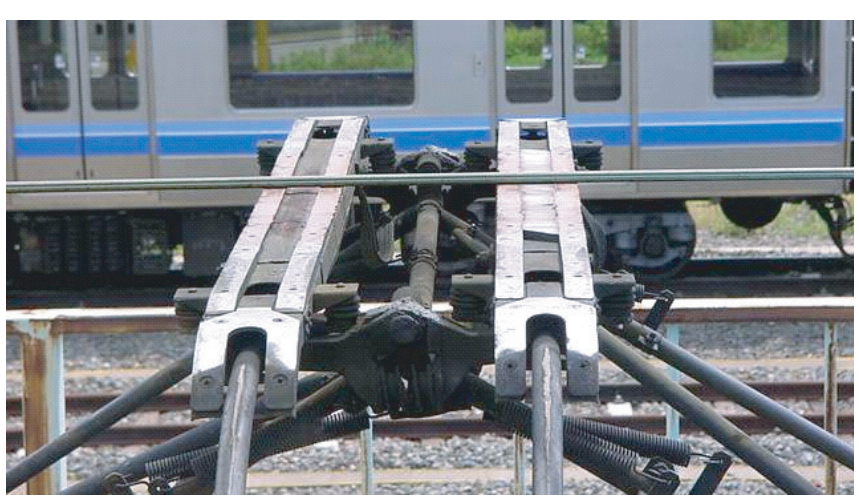

Fig. 4 Pantograph of train set used on JR Tozai Line

\section{Abnormal contact wire wear}

Abnormal wear on the sliding surface of the contact wire appeared soon after the line was commissioned for

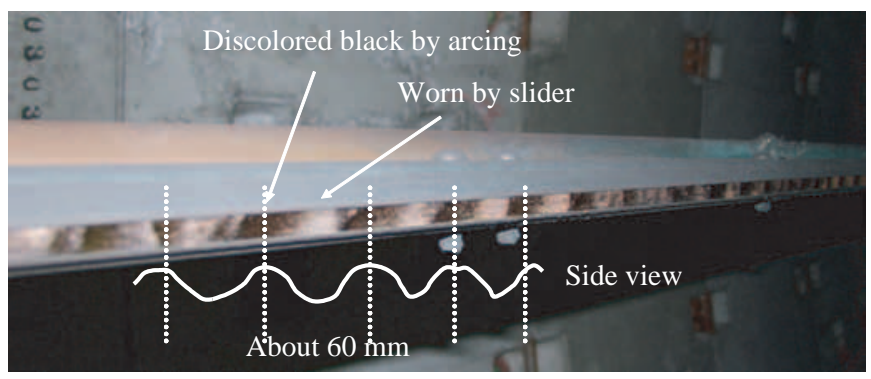

Fig. 5 Undulating wear on sliding surface of contact wire

revenue service. The worn portion appeared discolored black by arcing and another portion worn by the slider appeared at intervals of about $60 \mathrm{~mm}$, as shown in Fig. 5 . Such phenomena had already been recognized and termed as undulating wear ${ }^{1}$. Although it was well-known for undulating wear to be generated on low-speed sections near stations, the wear on the JR Tozai Line appeared on a section where trains run at speeds exceeding $50 \mathrm{~km} / \mathrm{h}$. Reference [1] shows the cause and its countermeasure, of which the details relevant to this paper can be summarized as follows:

As shown in Fig. 6, undulating wear forms and progresses when the sliding surface of a contact wire and a pantograph slider alternately repeat states (a) and (b). In the case of state (a), when solid lubricant wax, an electrical insulator, is applied on the convex of the contact wire, arcing occurs between hollows in the contact wire and the slider. In order to reduce such undulating wear, a normally effective countermeasure is to remove the solid lubricant wax from one side, as shown in Fig. 7. However, undulating wear has still occurred on the JR Tozai Line despite this countermeasure having been taken. This

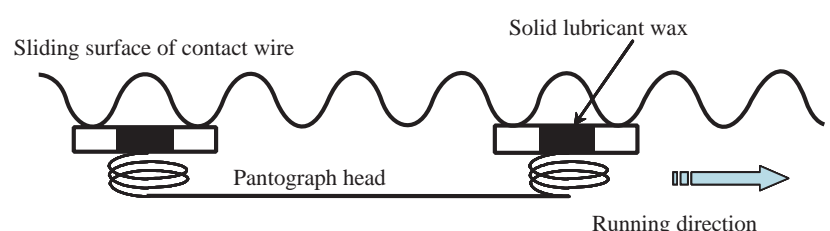

(a) State where slider touches contact wire

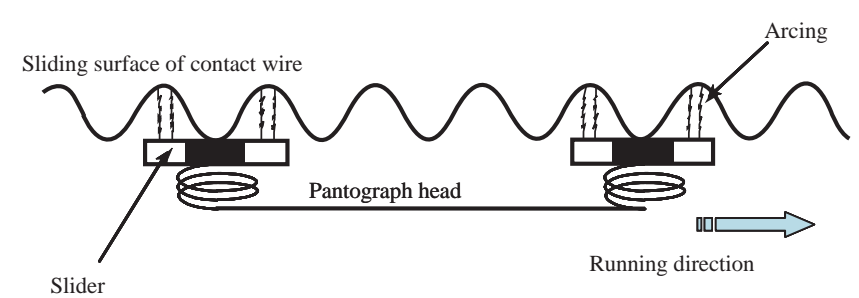

(b) State where slider does not touch contact wire

Fig. 6 Mechanism of undulating wear occurring on contact wire

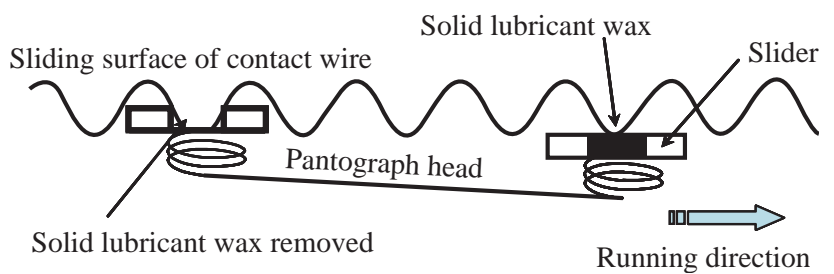

Fig. 7 General countermeasure against undulating wear 
showed that the contact loss performance further deteriorates as the train speed increases and that removing the solid lubricant wax from one side was ineffective.

\section{Uneven contact wire surface}

It is conceivable that the contact loss performance of the rigid conductor line, which is not as elastic as that on a catenary system, is very much related to contact wire unevenness. In theory, the mechanism shown in Fig. 6 would never occur on smooth and even sliding contact wire surfaces. Therefore, it is highly likely that such unevenness had formed soon after the contact wire was constructed. A rigid conductor line to the same specification as that on the JR Tozai Line was temporarily installed on RTRI premises; the degree of unevenness on the contact wire was investigated and compared to that found on the contact wires installed at the existing line site.

\subsection{Measuring method for surface unevenness}

Fig. 8 shows the measurement principles for applying the method generally used for track inspections. Under this method, an amplitude value of the unevenness of a wavelength as a string length is outputted at double the real value, as outputs at longer wavelengths gradually decline; shorter wavelength outputs become 0 at one and a half times the string length. Therefore, it is necessary to combine two or more string lengths to detect the unevenness of longer wavelengths. Two strings, one $80 \mathrm{~mm}$ long and the other $160 \mathrm{~mm}$, were adopted to enable detection of unevenness at wavelengths ranging from $50 \mathrm{~mm}$ through $500 \mathrm{~mm}$.

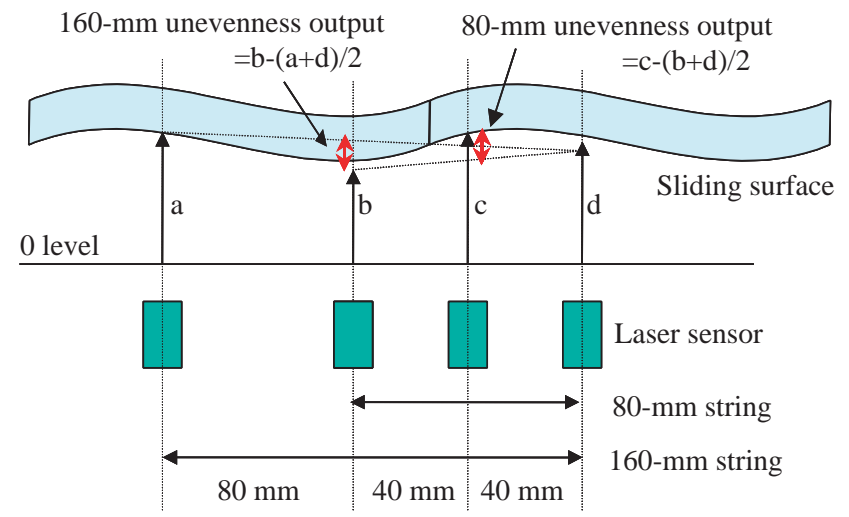

Fig. 8 Measuring contact wire unevenness

\subsection{Simulation outline}

A temporary $37.5 \mathrm{~m}$-long rigid conductor line was installed and supported at eight points with a height of 1.8 $m$ between the contact wire and the top of the rail, as shown in Fig. 9. Table 1 shows the kinds of contact wires used in each case and their respective installation methods. A stretching machine was adopted to rectify any bends in the contact wire, which was achieved by winding it around a drum, as shown in Fig. 10. In addition, perpendicularly wound contact wires (Table 1, Case B) have been used on the JR Tozai Line for ease of construction.

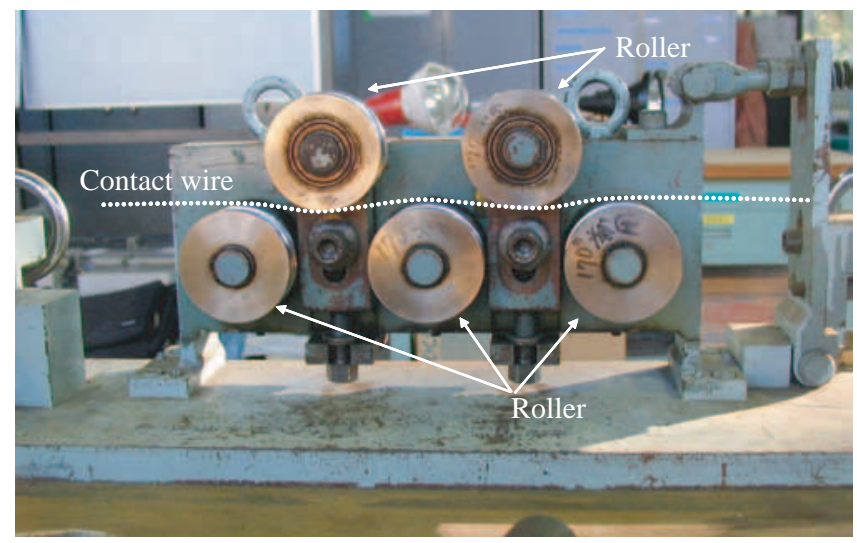

Fig. 10 Contact wire stretching machine

Table 1 Kinds of contact wires and fabrication details

\begin{tabular}{|c|c|c|c|}
\hline & Case A & Case B & Case C \\
\hline Contact wire & & $\begin{array}{c}\text { GT-Sn } \\
170 \mathrm{~mm}^{2}\end{array}$ & $\begin{array}{c}\text { GT-Sn } \\
170 \mathrm{~mm}^{2}\end{array}$ \\
\hline $\begin{array}{c}\text { Wind direction on } \\
\text { contact wire }\end{array}$ & & $\begin{array}{c}\text { Perpendi- } \\
\text { cular }\end{array}$ & Sideways \\
\hline Stretching machine & & Used & Not used \\
\hline Notes & Mount only & $\begin{array}{c}\text { Same as } \\
\text { JR Tozai Line }\end{array}$ & \\
\hline
\end{tabular}

\subsection{Measured results}

Fig. 11 shows a comparison of the simulated unevenness waveforms in Cases A, B and C (measured using the $160 \mathrm{~mm}$ string). Periodic waves appeared when the perpendicularly wound contact wire was adopted and the stretching machine used (Case B). On the other hand, such waves didn't appear when the sideways-wound contact wire was adopted with no stretching machine use

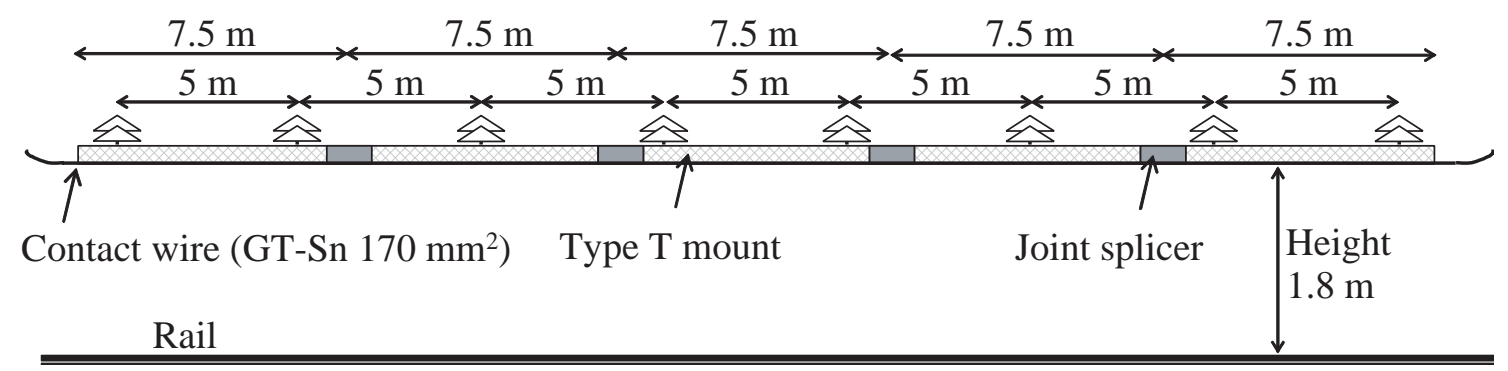

Fig. 9 Rigid conductor test line 


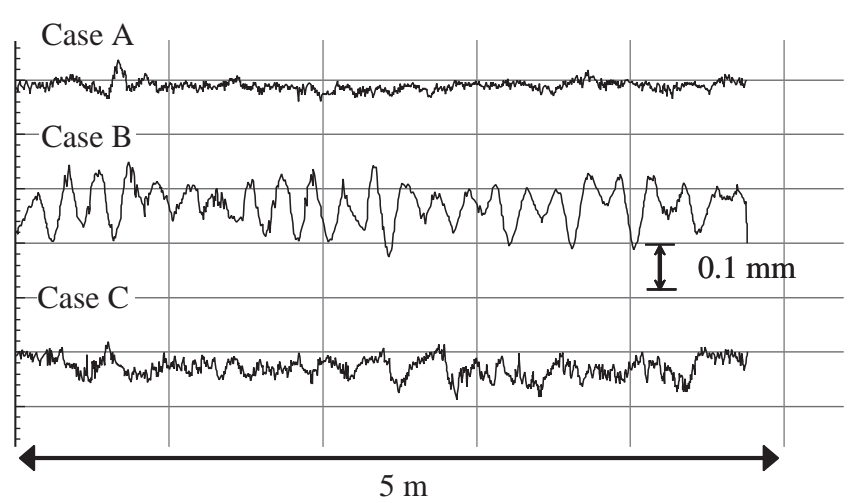

Fig. 11 Simulated unevenness waveforms

(Case C). Fig. 12 shows the waves that passed the wave filter ( $350 \sim 450 \mathrm{~mm}$ or $150 \sim 250 \mathrm{~mm}$ band widths). In Case B, contact wire surface unevenness was induced by using the stretching machine and that compounded the unevenness at $200 \mathrm{~mm}$ and $400 \mathrm{~mm}$ wavelengths. Surface unevenness was barely detectable in Case A (mount only).

Fig. 13 shows the power spectrum density for Cases $\mathrm{B}$ and $\mathrm{C}$ together with the field data. Case $\mathrm{B}$, which is the same as that on the JR Tozai Line, is well in agreement with the field data; an unevenness of $200 \mathrm{~mm}$ was formed under the effect of the stretching machine and the unevenness of $400 \mathrm{~mm}$ : there was a gap between the bolts

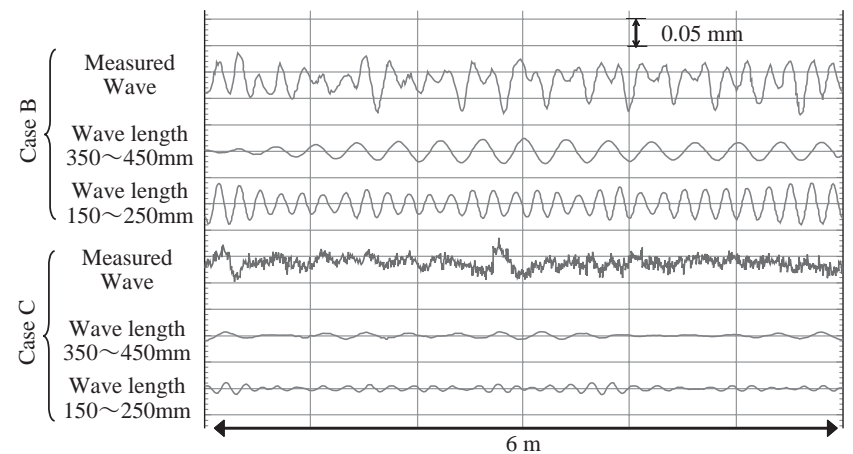

Fig. 12 Waves that passed wave filter

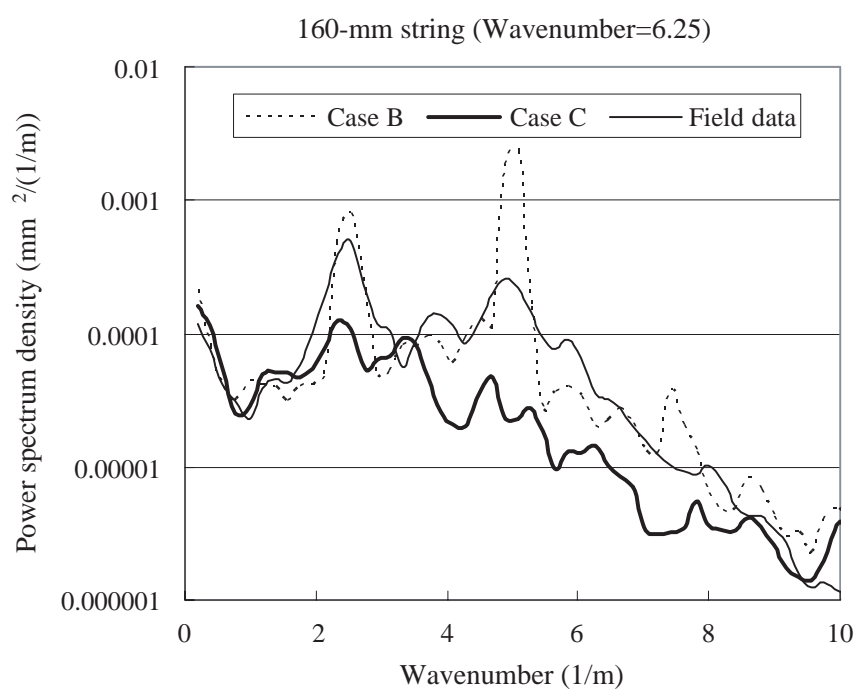

Fig. 13 Power spectrum density characteristics which attach the contact wire to the mount. In addition, the sideways-wound contact wire (Case C), for which the stretching machine not used, had little unevenness compared with others. As mentioned above, though the stretching machine is capable of removing a long-wavelength bend, it is highly likely to generate another unevenness with a specific wavelength of approximately $200 \mathrm{~mm}$. It becomes impossible for the pantograph to follow such unevenness as the train speed increases. This is considered to be the cause of undulating wear.

\section{Improving quality by removal of contact wire surface unevenness}

\subsection{Changes in unevenness after grinding}

This chapter verifies the adverse effect on current collection caused by contact wire unevenness. After grinding the sliding surface of a contact wire with a grinding machine, a current collection performance comparison was made. The grinding machine ${ }^{2)}$ removes the unevenness with a wavelength of less than about $500 \mathrm{~mm}$, while forcing the grindstone and applying a certain amount of force on the sliding surface. Table 2 shows the grinding

Table 2 Grinding machine specifications

\begin{tabular}{|l|l|}
\hline \multicolumn{1}{|c|}{ Item } & \multicolumn{1}{|c|}{ Specifications } \\
\hline Grinding system & Wheel \\
\hline Types of grinding wheels & For copper, iron \\
\hline Amount of vertical movement & $400 \mathrm{~mm}$ \\
\hline Amount of right and left deviation movement & $600 \mathrm{~mm}$ \\
\hline Grinding pressure & $0 \sim 500 \mathrm{~N}$ \\
\hline Amount of cutting control & $0.02 \mathrm{~mm}$ \\
\hline Mass & About $400 \mathrm{~kg}$ \\
\hline Grinding speed & About $3 \mathrm{~km} / \mathbf{h}$ \\
\hline
\end{tabular}

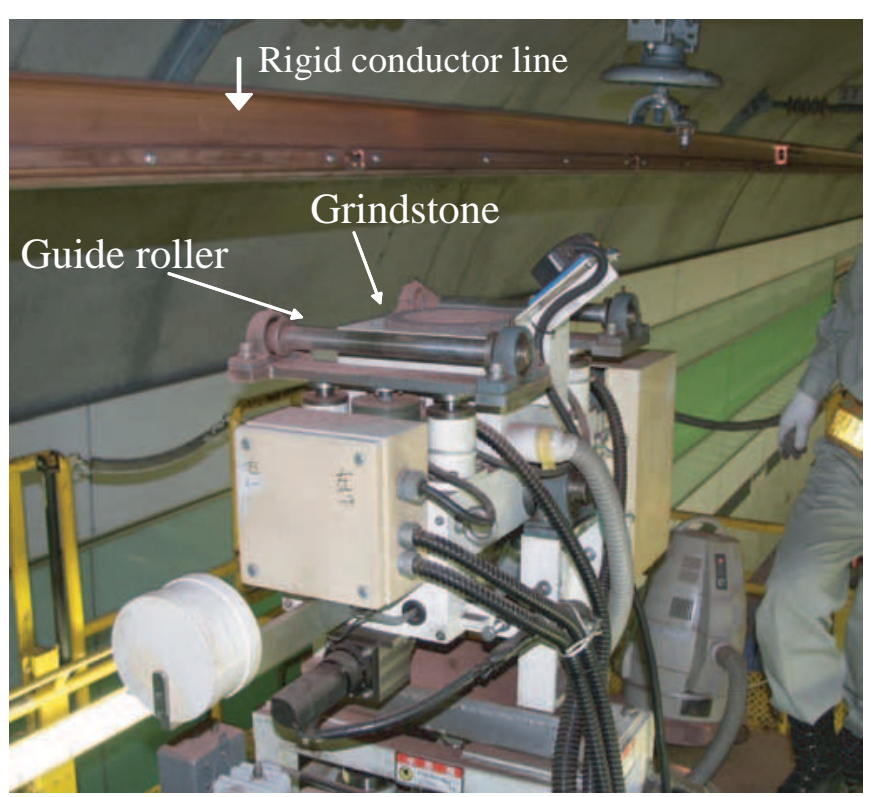

Fig. 14 View of grinding machine setup 

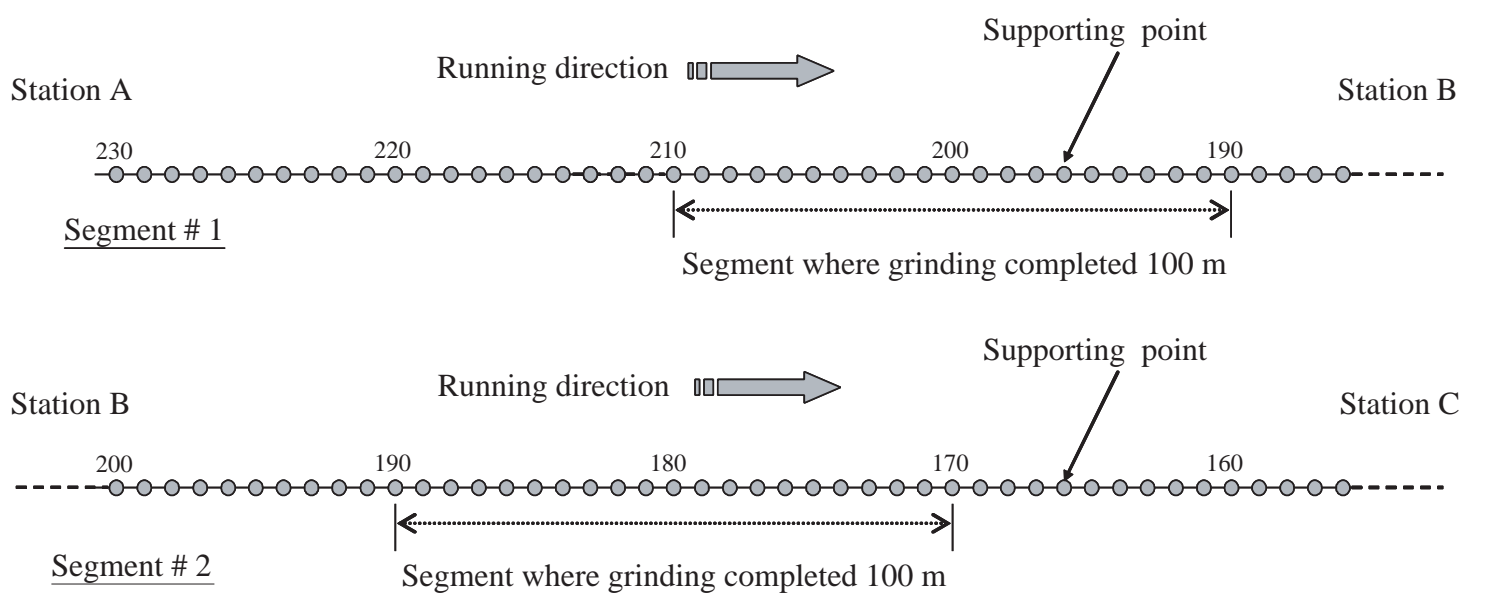

Fig. 15 Two grinding segments
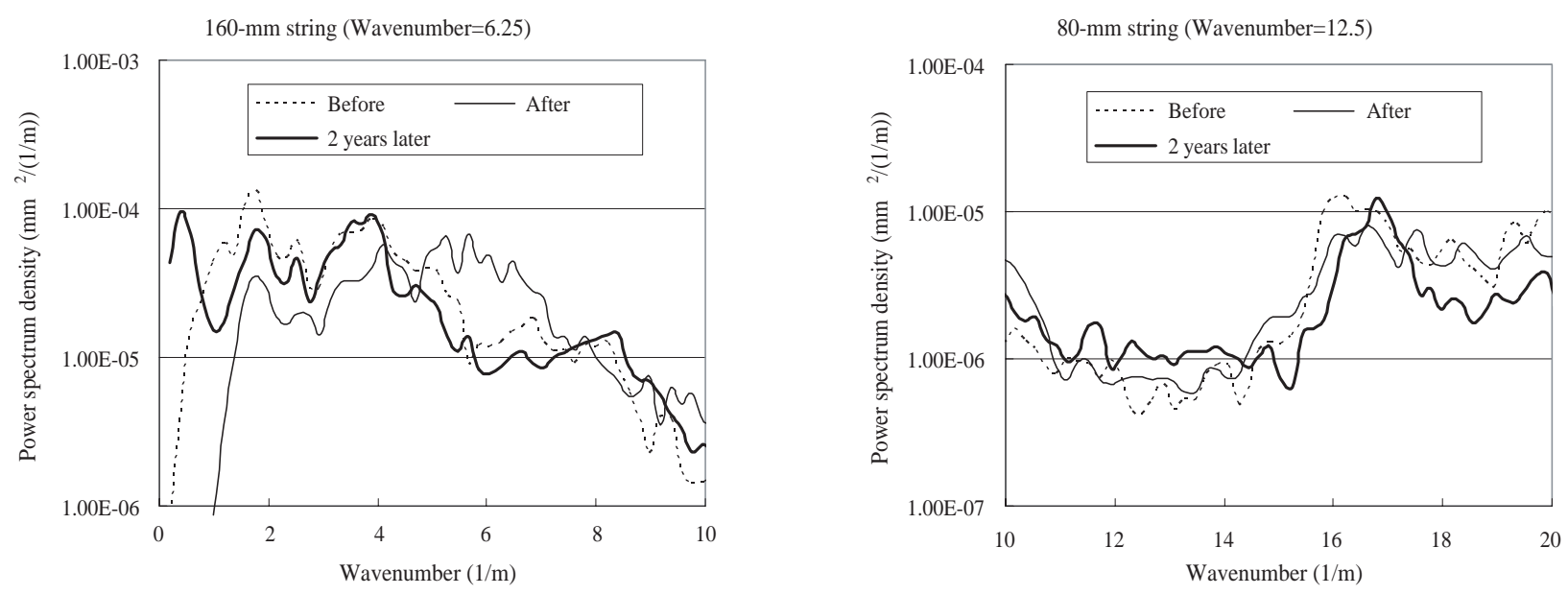

(a) Segment \# 1
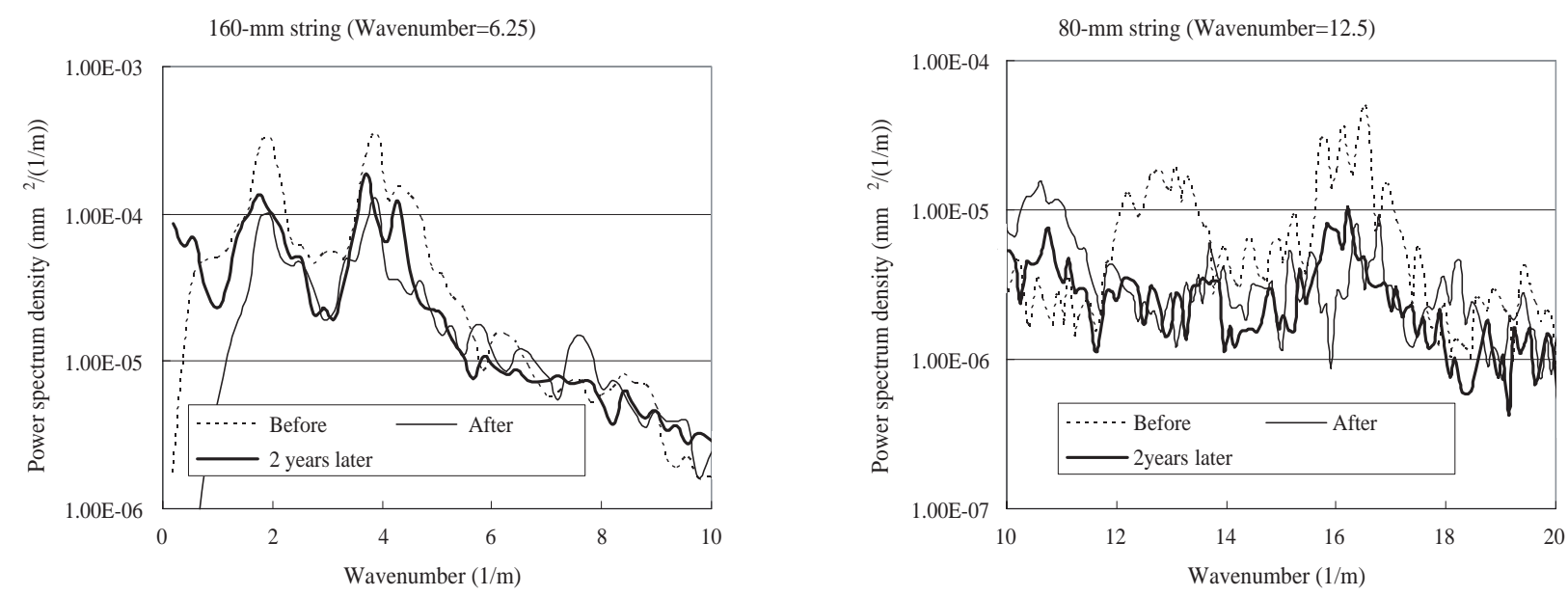

(b) Segment \# 2

Fig. 16 Power spectrum density characteristics in two grinding sections

machine specifications and Fig. 14 its setup. The grinding machine uses a grindstone normally used for copper and iron and can smooth the unevenness continuously. It is mounted on a maintenance car and when grinding runs at a speed of about $3 \mathrm{~km} / \mathrm{h}$. Fig. 15 shows two segments where grinding was completed, Fig 16 the power spec- trum density of the sliding surface of the contact wires measured at the two segments. As is apparent from Fig. 16(a), a significant difference was not observed before and after the grinding work, or even two years later, due to the insufficient grinding work carried out at segment \# 1. However, in the case of the segment \# 2, at a wave 


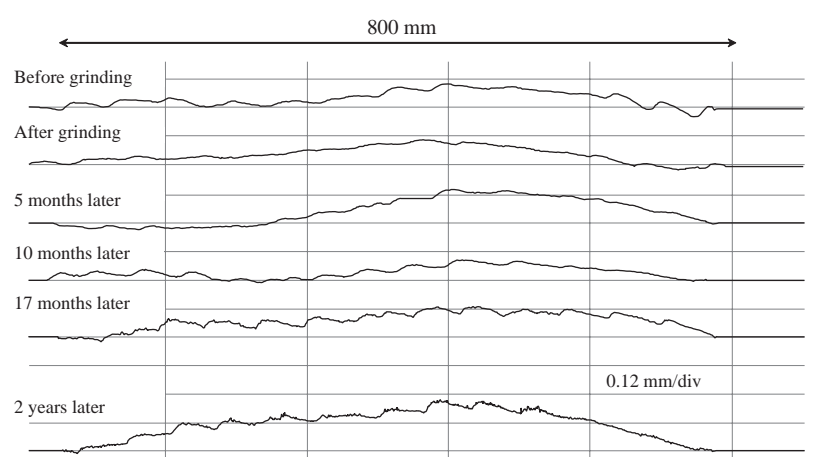

(a) Part of grinding segment \# 1

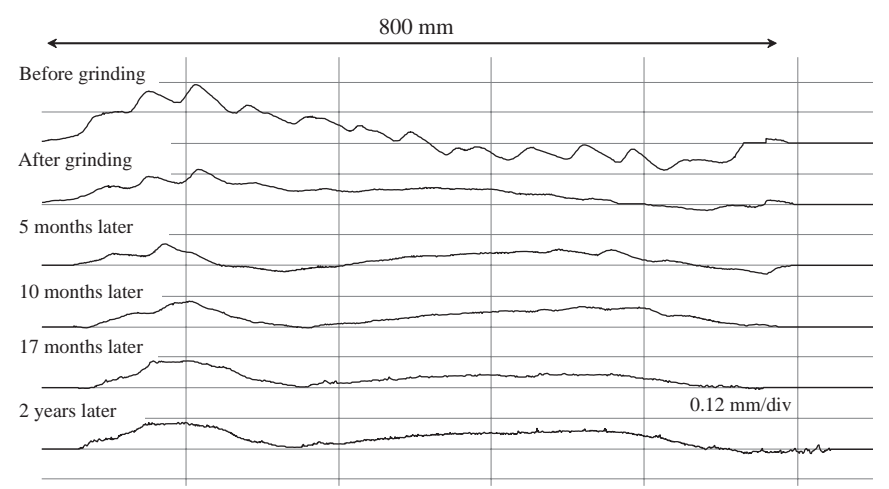

(b) Part of grinding segment \# 2

Fig. 17 Changes in appearance of contact wire sliding surfaces

number of two through five: $200 \mathrm{~mm}$ through $500 \mathrm{~mm}$ was considered as initial wear; at a wave number of 13 , a wavelength of about $80 \mathrm{~mm}$; and at a wave number of 16 undulating wear with a wavelength of $60 \mathrm{~mm}$ decreased by comparison with the previous condition. Such a condition remained the same even after two years. For reference, Fig. 17 illustrates changes in appearance of two sliding surface segments after grinding. As seen from the Figure, an undulating wear wavelength of nearly $60 \mathrm{~mm}$ reappeared after the grinding at segment \# 1 , but no undulating waves have been observed at segment \# 2 . In view of the above facts, it is evident that conditions immediately after the construction of contact line construction have a great effect on the occurrence of such wear.

\subsection{Current collection performance tests}

We conducted a train running field test to verify current collection performance measured before and after grinding the contact wires. As seen from Fig. 18, two principal parameters were applied during measurement, one of which indicated the voltage drop due to contact loss, the other an optical method to detect arcing caused by contact loss. Fig. 19 shows the measurement results of the contact loss rate after grinding, which decreased compared with the previously measured rate.

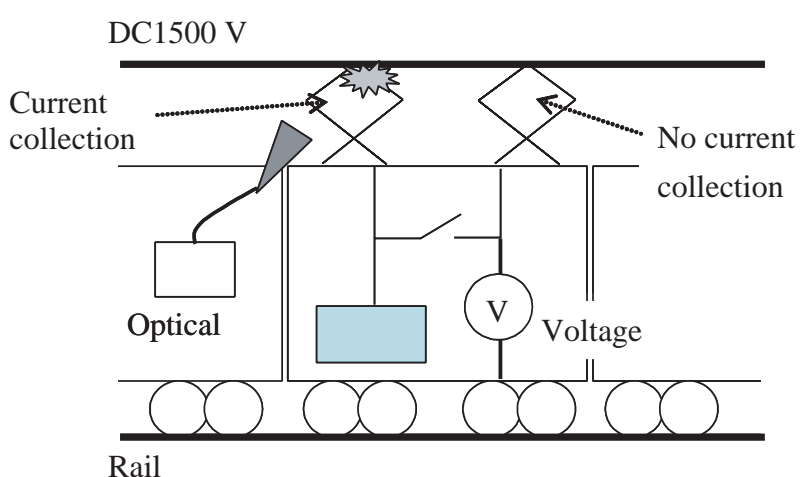

Fig. 18 Field test outline

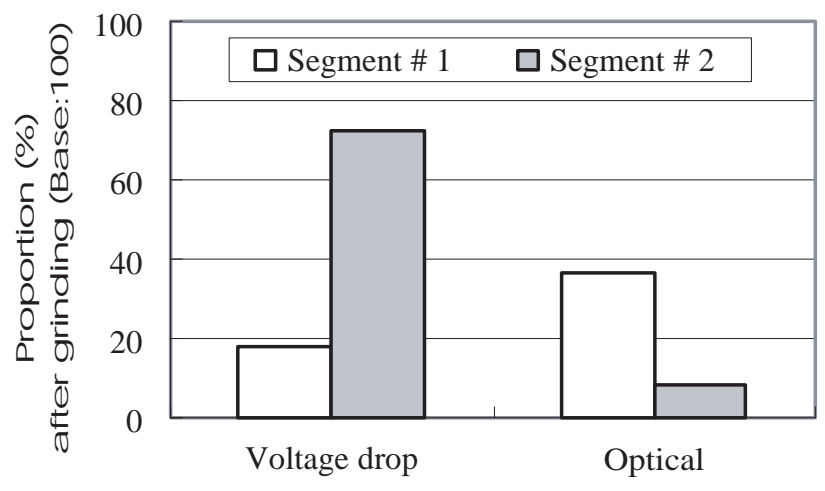

Fig. 19 Results of contact loss rate measurement

\section{Conclusions}

In this paper, we investigated the cause of undulating wear generated on Type T rigid conductor lines on JR commercial lines and proposed a countermeasure to improve current collection quality. The summarized results are as follows:

(1) Abnormal wear on rigid conductor lines on the JR Tozai Line was mainly undulating wear due to contact loss occurring at intervals of about $60 \mathrm{~mm}$.

(2) On perpendicularly wound contact wire, $200 \mathrm{~mm}$ unevenness formed due to the effect of stretching machine use, and $400 \mathrm{~mm}$ unevenness of due to a gap in the bolts that attach the contact wire to a mount. This appearance agrees well with JR Tozai Line's field data.

(3) In the case of sideways-wound contact wires with no stretching machine use, $200 \mathrm{~mm}$ unevenness does not exist at all, and $400 \mathrm{~mm}$ unevenness is more suppressed.

(4) Since the contact loss is minimized on a smooth-surfaced contact wire, undulating wear will be never generated.

(5) As mentioned above, it is evident that the unevenness that forms on contact wires at the time of replacement largely dictates whether undulating wear will appear or not. It is therefore desirable to reduce contact wire unevenness at the time of construction to improve the quality of rigid conductor lines. 


\section{References}

1) AOSHI, M., and NAGASAWA, H., "Development of Countermeasure against Undulating Wear of Contact Wire on Narrow-Gauge Lines," RTRI Report, Vol. 6,
No. 7, pp. 37-44, 1992 (in Japanese)

2) MANDAI, T., SHIMIZU, M. et al., "Improvement of Rigid Conductor Lines," RTRI QR, Vol. 44, No. 2, pp. 78-81, May 2003 